\title{
Evaluation of Thrombolytic, Membrane Stabilizing, Antidiarrhoeal and Analgesic Activities of Leaves of Triumfetta pilosa
}

\author{
Tanvir Ahmed, Amiyo Bala, Jalal Uddin and Zubair Khalid Labu \\ Department of Pharmacy, World University of Bangladesh, Dhaka-1205, Bangladesh
}

Received: March 27, 2016; Accepted: July 25, 2016; Published (Web): July 31, 2016

\begin{abstract}
The aim of the research has been focused on the phytochemical investigation of the plants which have ethnobotanical and folkloric importance for drug discovery. The widespread availability and folkloric use of Triumfetta pilosa leaves led us to determine the pharmacological potential of the plant through in vitro and in vivo experiments. The crude ethanolic extract (EE) of $T$. pilosa leaves were partitioned successively using solvent of different polarities. Then these fractions were subjected to qualitative and quantitative phytochemical screening by standard procedures. The extract of $T$. pilosa and its fractions were evaluated for their possible thrombolytic, membrane stabilizing, antidiarrhoeal and analgesic activities by using standard drugs streptokinase, acetyl salicylic acid, loperamide and diclofenac-Na, respectively. In the study for thrombolytic activity, among all partitionates, the ethyl acetate soluble fraction (ESF) showed the highest percent of clot lysis $(58.67 \%)$ as compared to standard streptokinase $(69.23 \%)$ and water $(3.77 \%)$. Also, in case of membrane stabilizing activity, ESF significantly inhibited the haemolysis of human erythrocyte membrane both induced by hypotonic solution $(65.33 \pm 0.50 \%)$ and heat $(56.22 \pm 0.69 \%)$, as compared to standard acetyl salicylic acid (ASA) $(71.12 \pm 26 \%)$ and $(75.92 \pm 0.29 \%)$, respectively. In the antidiarrheal assay, the crude ethanolic extract inhibited the mean number of defecation by $45.71 \%$ and $63.18 \%$ at 200 and $400-\mathrm{mg} / \mathrm{kg}$ body weight, respectively. During assay for central and peripheral analgesic activity at dose of $400-\mathrm{mg} / \mathrm{kg}$, the extract showed reaction times of $5.11(\mathrm{p}<0.001)$ and $1.96(\mathrm{p}<0.001) \mathrm{min}$ in the tail-flick and tail-immersion models, while the normal and reference groups exhibited reaction times of 11.66, 1.46; (p $<0.001)$ and 4.91, 1.16; ( < 0.001) in the tail flick and tail immersion method, respectively. At $400 \mathrm{mg} / \mathrm{kg}$, the extract showed $49.22 \%$ inhibition of acetic acid induced writhing in mice model.
\end{abstract}

Key words: Triumfetta pilosa, thrombolytic, membrane stabilizing, antidiarrhoeal, analgesic activities

\section{Introduction}

Numerous plants possess active medicinal values and are used to treat many diseases in various cultures worldwide and contribute as raw plant materials, refined crude extracts and mixtures to most of the medicinal preparations (Farnsworth, 1996). Although the toxicity profile of the most medicinal plants have not been thoroughly evaluated, it is well accepted because of its effectiveness, low cost and availability than their synthetic counterparts (Zengin et al., 2012). Triumfetta pilosa locally known as 'Bouthorani' is a fast growing perennial shrub belonging to the family Malvaceae. It can grow in light as well as the heavy soils under the tropical conditions. To grow, it requires proper sunlight and irrigation during the monsoon season. It starts bearing fruits after seven years from the day of plantation. Due to its special taste pilosa fruits are well accepted by the people. It is generally propagated through seeds. It has both superoxide dismutase and vitamin $\mathrm{C}$ in large amount (Vongtau et al., 2005; Oluyemi et al., 2007). The mature fruits are very sour and contain 1\%-1.8\% vitamin C. They are eaten raw or sweetened or preserved. The dried leaves are sometimes used as pillow filler. $T$. pilosa is a popular medicinal plant in traditional way to treat various diseases such as bleeding piles, vomiting, gout, asthma, heart and bladder diseases, sore throat, hiccough, diarrhea in

Correspondence to: Zubair Khalid Labu; Tel.: +88-01558388956; E-mail: zubair.labu@ yahoo.com 
Bangladesh (Kirtikar et al., 1993). It is also used in various traditional medicinal systems, such Ayurvedic medicine, Chinese herbal medicine, and Tibetan medicine (Zhang et al., 2001). Based upon previous ethnobotanical literatures and potential medicinal values as judged by local users and healers, the plant was selected to investigate for thrombolytic, membrane stabilizing, antidiarrhoeal and analgesic activities.

\section{Materials and Methods}

Plant materials: The mature leaves of $T$. pilosa were collected from the National Botanical Garden, Dhaka, Bangladesh in August, 2014 and were confirmed by the taxonomist of Bangladesh National Herbarium, Mirpur, Dhaka. Voucher specimen (DACB accession no. 36703) has been deposited in Bangladesh National Herbarium according to the official system.

Preparation of extract: To avoid the loss of essential plant components, the collected leaves were shade dried for several days and then oven dried for 24 hours at $37{ }^{\circ} \mathrm{C}$ to facilitate grinding, passing through sieve \# 40. The powdered leaves were then preserved in a tight container. The dried powder material (400 gm) obtained from about $2.5 \mathrm{~kg}$ fresh matured leaves was soaked in $1500 \mathrm{ml}$ of $90 \%$ ethanol for two weeks and shaken occasionally. The whole mixture was filtered by a piece of clean white cotton followed by Whatman filter paper. The filtrate was dried using a vacuum rotary evaporator under reduced pressure and temperature $\left(40{ }^{\circ} \mathrm{C}\right)$ to yield $9.5 \mathrm{gm}$ of the crude extract of T. pilosa. The concentrated aqueous ethanol extract was partitioned by the Kupchan method and the resultant partitionates, i.e. ethyl acetate (ESF), petroleum ether (PSF), carbon tetrachloride (CTSF), chloroform (CSF) and aqueous soluble fractions (AQSF) were then used for the current investigation.

\section{Phytochemical screening}

The freshly prepared organic extracts were qualitatively tested for the presence of various categories of phytochemicals. These were identified by characteristic color changes in standard procedures, which were described by Sofowara (1993).

Determination of total flavonoid content: The total flavonoid content was estimated using a previously described method using quercetin as a reference compound (Kumaran et al., 2004).

Determination of total tannin content: The total tannin content of $T$. pilosa was determined by FolinCoicalteu reagent (Kim et al., 2003).

\section{In vitro thrombolytic activity}

The thrombolytic activities of prepared ethanolic extract and its fractions were evaluated by the method described by Daginawala et al. (2006).

\section{In vitro membrane stabilizing assay}

The membrane stabilizing activity of the crude EE and soluble partitionates was assessed by evaluating their ability to inhibit hypotonic solution and heatinduced haemolysis of human erythrocytes following the method developed by Shinde et al. (1989).

Hypotonic solution-induced hemolysis: The assessment was carried out with hypotonic solution. The absorbance of the supernatant was measured at 540 $\mathrm{nm}$ using UV-Visible spectrophotometer. The percentage inhibition of either haemolysis or membrane stabilization was determined using the following equation.

$\%$ inhibition of haemolysis $=100 \times\left\{\left(\mathrm{OD}_{1}-\mathrm{OD}_{2}\right) / \mathrm{OD}_{1}\right\}$

Where, $\mathrm{OD}_{1}=$ Optical density of hypotonic buffered saline solution alone (control) and $\mathrm{OD}_{2}=$ Optical density of the test sample in hypotonic solution.

Heat-induced haemolysis: Isotonic buffer solution containing $2 \mathrm{mg} / \mathrm{ml}$ of EE and different fractions of $T$. pilosa were put into two duplicates of centrifuging tube.

\section{Test for antidiarrhoeal activity}

Test animals and drugs: White albino mice (Swisswistar strain, body weight: 20-25 gm) of either sex aged 4-5 weeks were collected for the in vivo antidiarrhoeal activity. They were kept in standard environmental conditions at animal house of Pharmacology Laboratory, World University of Bangladesh, Dhaka. Experiments with the animals were performed in accordance with guidelines of the Institutional Animal Ethics Committee. Loperamide (Square Pharmaceuticals Ltd., Bangladesh) was used as standard drug for this study. 
Castor oil-induced diarrhoea: To evaluate antidiarrhoeal activity of ethanolic extract of $T$. pilosa by using castor oil-induced diarrhoea in mice, the standard procedure was followed according to Shoba et al. (2001). The time for first excretion of feces and the total number of faecal output by the animals were recorded and the inhibition of defecation in mice was calculated by using the following equation:

$\%$ inhibition $=[(\mathrm{Mo}-\mathrm{M}) / \mathrm{Mo}] \times 100$;

Where, Mo $=$ Mean defecation of control and $\mathbf{M}=$ Mean defecation of test sample.

\section{Analgesic studies}

Hot plate method: Hot plate test was used to measure the response latencies based on the procedure described by Eddy and Leimbach (1953). In this experiment, the hot plate was maintained at $55 \pm 0.5^{\circ} \mathrm{C}$. The reaction time was recorded for animals pretreated with, Group-I animals received $0.5 \% \mathrm{Na}$ - CMC (0.1 $\mathrm{ml} / 10 \mathrm{gm}$ ) as control, Group-II received, diclofenac-Na (1 $\mathrm{mg} / \mathrm{kg}$, b.w. intraperitoneally, $30 \mathrm{~min}$ before administration of $\mathrm{Na}$ - CMC) was used as positive control. Groups-III, IV and V animals received the extract at 100-, 200-, 400-mg/kg bw. Animals were placed onto the hot plate chamber and the time of latency was determined.

Tail immersion method: The tail-flick test was conducted as per the method modified by D'Amour and Smith (1941).

Acetic acid-induced writhing test: The abdominal constriction was induced in mice (weighing 25-30 gm) by intraperitoneal injection of $1 \%(\mathrm{v} / \mathrm{v})$ acetic acid $(2.3$ $\mathrm{ml} / \mathrm{kg}$ ), as described by (Koster et al., 1949). The percentage inhibition of analgesic activity was calculated by using following formula:

$$
\% \text { Analgesic activity }=\frac{\text { Mean writhing count }(\text { Control group }- \text { Treated group) }}{\text { Mean writhing count of control group }} \times 100
$$

Statistical analysis: Three replicates of each sample were used for each test to facilitate statistical analysis and the data are presented as mean \pm standard deviation $(\mathrm{SD})$ mean \pm SEM.

\section{Results and Discussion}

Identification of chemical classes of constituents: Phytochemical screening of the crude ethanolic extract and fractionates of $T$. pilosa leaves showed the presence of alkaloids, flavonoids, tannins, carbohydrates, steroids and reducing sugars.

The ethanolic extract of $T$. pilosa and its different Kupchan fractionates were isolated and subjected to examination for total phenolic and flavonoid content as well as thrombolytic, membrane stabilizing, antidiarrhoeal and analgesic activities.

Total flavonoid and tannin content: Since, all the fractions demonstrated positive results for flavonoids and tannin in the preliminary phytochemical screening, these were quantified. In this investigations, CTSF exhibited the highest flavonoid content $(97.37 \pm 0.25$ $\mathrm{mg} / \mathrm{gm})$ while PSF had the lowest flavonoid content $(33.44 \pm 0.47 \mathrm{mg} / \mathrm{g})$. The total tannin content was highest in petroleum ether soluble fraction (62.47 \pm $0.33 \mathrm{mg} / \mathrm{gm})$ whereas ethanolic extract was $(26.98 \pm$ $0.49 \mathrm{mg} / \mathrm{gm}$ ) had the lowest in amount (Table 1).

Table 1. Total flavonoid, tannin content of ethanolic extract of $T$. pilosa.

\begin{tabular}{lcc}
\hline Extracts & $\begin{array}{c}\text { Total flavonoids } \\
\text { content (mg of } \\
\text { QAE/gm) of dry } \\
\text { extract }\end{array}$ & $\begin{array}{c}\text { Total tannins } \\
\text { content (mg of } \\
\text { TAE/gm) of dry } \\
\text { extract }\end{array}$ \\
\hline ESF & $37.37 \pm 0.25$ & $27.08 \pm 0.22$ \\
CTSF & $97.37 \pm 0.25$ & $35.09 \pm 0.11$ \\
PSF & $33.44 \pm 0.47$ & $62.47 \pm 0.33$ \\
EE & - & $26.98 \pm 0.49$ \\
\hline
\end{tabular}

Results are expressed as mean $\pm \mathrm{SD}(\mathrm{n}=3)$, are statistically significant $(\mathrm{p}<0.05)$.

Thrombolytic activity: In vitro thrombolytic activity study the positive control showed $69.25 \%$ lysis of clot, while sterile distilled water, a negative control exhibited a negligible percentage of lysis of clot $(3.77 \%)$. The ethanolic extract $(43.28 \%)$, ethyl acetate soluble fraction $(58.67 \%)$, chloroform extract $(52.5 \%)$, 
pet ether soluble fraction (57.67\%) and aqueous soluble fraction showed $(22.81 \%)$ varying degrees clot lysis. In this study, it was observed that the ethyl acetate soluble fraction of $T$. pilosa showed highest thrombolytic activity. Hence, the obtained results were compared with the control groups where, ${ }^{*} \mathrm{p}$ values $<0.005$, ${ }^{* *} \mathrm{p}<$ 0.001 considered statistically significant (Table 2). The results from the study clearly shows that $T$. pilosa extract is a potent clot lysis agent.

Membrane stabilizing activity: In vitro membrane stabilizing activity study revealed that, at $2 \mathrm{mg} / \mathrm{ml}$ the crude mextract and its partitionates of significantly protected the haemolysis of human erythrocyte membrane induced by hypnotic solution and heat as compared to the standard ASA. ESF of $T$. pilosa inhibited significant percentage $(65.33 \pm 0.35 \%)$ of hemolysis of RBC induced by hypnotic solution and $(56.22 \pm 0.69 \%)$ by heat, respectively. So from the observed results, it can be interred that the significant inhibition of erythrocyte lysis by T. pilosa leaves could be the possible mechanism of its anti-inflammatory activity.

Test for antidiarrhoeal activity: The result showed that the ethanolic extract reduced the mean number of defecation by $45.71 \%(\mathrm{p}<0.01)$ and $63.18 \% \& \mathrm{p}<0.001)$ at the doses of $200-$ and $400-\mathrm{mg} / \mathrm{kg}$, respectively in comparison with standard drug $(71.38 \%)$. The extract also reduced the frequency of defecation or prolongation of defecation time by almost $48.84 \%$ and $62.79 \%$ at the dose of $200-$ and $400-\mathrm{mg} / \mathrm{kg}$ body weight, respectively The latent period for the extract treated group was $(\mathrm{p}<0.01$ and $\mathrm{p}<0.001)$ increased as compared to control group (Table 3). Literature review suggests that the presence of tannins and flavonoids in any medicinal plants would allow it to act as remedy for diarrhoea (Burdock et al., 2006).

Table 2. Membrane stabilizing and thrombolytic activity (in terms of \% clot lysis) of different fractions of $T$. pilosa.

\begin{tabular}{lccc}
\hline Samples & \multicolumn{2}{c}{$\%$ Inhibition of haemolysis (mean \pm SD) } & \% of clot lysis \\
\cline { 3 - 4 } & Heat-induced & Hypotonic solution-induced & \\
\hline Hypotonic medium & - & - & $57.67 * *$ \\
PSF & $49.33 \pm 0.61$ & $52.33 \pm 0.64 *$ & $58.67 * *$ \\
ESF & $56.22 \pm 0.69 *$ & $65.33 \pm 0.64 * *$ & $52.5 * *$ \\
CTSF & $46.22 \pm 0.57$ & $49.66 \pm 0.77 *$ & $22.81^{*}$ \\
AQSF & $30.34 \pm 0.42$ & $33.49 \pm 0.51 *$ & - \\
ASA & $71.12 \pm 0.26^{*}$ & $75.92 \pm 0.29 *$ & $43.28^{*}$ \\
EE & - & - & $69.25^{* *}$ \\
SK & - & - & $3.77^{*}$ \\
BLANK & - & - & \\
\hline
\end{tabular}

Values are expressed as mean $\pm \mathrm{SD}$ (standard deviation); $* \mathrm{P}<0.005$, **P $<0.001$; statistically significant as compared to positive control and negative control.

Table 3. Antidiarrhoeal activity of the ethanolic extract of leaves of T. pilosa.

\begin{tabular}{llccc}
\hline Sample & Dose & \multicolumn{3}{c}{ Mean \pm SD } \\
\cline { 2 - 4 } & & Latent period & Defecation & \% Inhibition \\
\hline Distilled water & $1 \mathrm{ml} / \mathrm{mice}$ p.o & $0.79 \pm 0.06$ & $9.9 \pm 0.86$ & - \\
Loperamide & $50 \mathrm{mg} / \mathrm{kg}$ p.o & $2.21 \pm 0.16^{* *}$ & $3.9 \pm 0.45^{* *}$ & 71.38 \\
EE of $T$. pilosa & $200 \mathrm{mg} / \mathrm{kg} \mathrm{p.o}$ & $1.05 \pm 0.07^{*}$ & $5.9 \pm 0.86$ & 45.71 \\
& $400 \mathrm{mg} / \mathrm{kg}$ p.o & $1.59 \pm 0.19^{* *}$ & $5.1 \pm 0.63^{* *}$ & 63.18 \\
\hline
\end{tabular}

Values are expressed as mean \pm SEM (Standard Error Mean); * indicates $\mathrm{p}<0.01$; ** indicates $\mathrm{p}<0.001$, one-way ANOVA followed by Dunnet's test as compared to control; $\mathrm{n}=$ number of mice; $\mathrm{p} . \mathrm{o}$ : per oral. 
Tail immersion and hot plate test: The results obtained from analgesic studies are presented in tables 4 and 5 for tail flick and tail immersion methods, respectively. The extract showed statistically significant $(p<0.001)$ analgesic activity at all tested dose levels. The extract activity was statistically comparable to the reference drug employed in terms of analgesic activity. The reaction time of tail flick and tail-immersion showed for the reference drug (diclofenac-Na) and extract T. pilosa at a dose of $400 \mathrm{mg}$ being (4.9), (5.1) and (1.16), (1.99) respectively. These results are statistically significant ( $\mathrm{p}<0.001$ ), compared to control. The tail withdrawal reflex time following administration of the leave extract was found to increase with increasing dose of the extract. The tail immersion test was considered to be a selective method to study compounds acting through opioid receptor. Therefore, taking all these data together we believe that the analgesic activity of the extract is most likely to be mediated by central action (spinally and supraspinally) (Ahmadiani et al., 2000).

Table 4. Analgesic activity of the crude ethanolic extract of T. pilosa, evaluated by hot plate test method

\begin{tabular}{|c|c|c|c|c|c|c|}
\hline \multirow{2}{*}{$\begin{array}{l}\text { Test } \\
\text { group }\end{array}$} & \multirow[t]{2}{*}{ Treatment } & \multirow{2}{*}{$\begin{array}{l}\text { Dose } \\
\text { (mg/kg b.w) }\end{array}$} & \multicolumn{3}{|c|}{ Number of movement } & \multirow[b]{2}{*}{$90 \mathrm{~min}$} \\
\hline & & & $0 \mathrm{~min}$ & $30 \mathrm{~min}$ & $60 \mathrm{~min}$ & \\
\hline I & $\mathrm{Na}-\mathrm{CMC}$ & $0.1 \mathrm{ml} / \mathrm{mice}$ & $10.5 \pm 0.204$ & $8.5 \pm 0.204$ & $9.5 \pm 0.204$ & $11.66 \pm 0.192$ \\
\hline II & Diclofenac-Na & $5 \mathrm{mg} /$ mice & $3.33 \pm 0.192$ & $5.5 \pm 0.39 * *$ & $4.0 \pm 0.235^{* *}$ & $4.9 \pm 0.204 * *$ \\
\hline III & Extract & $100 \mathrm{mg} / \mathrm{kg}$ & $8.16 \pm 0.152$ & $7.5 \pm 0.39^{*}$ & $6.0 \pm 0.235^{* *}$ & $7.0 \pm 0.577 * *$ \\
\hline IV & Extract & $200 \mathrm{mg} / \mathrm{kg}$ & $6.3 \pm 0.192$ & $5.0 \pm 0.235^{* *}$ & $5.9 \pm 0.456^{*}$ & $6.83 \pm 0.459 * *$ \\
\hline V & Extract & $400 \mathrm{mg} / \mathrm{kg}$ & $3.3 \pm 0.192$ & $5.8 \pm 0.135^{* *}$ & $7.5 \pm 0.416^{*}$ & $5.11 \pm 0.856^{*}$ \\
\hline
\end{tabular}

Values are expressed as mean \pm SEM; * indicates $\mathrm{p}<0.01 ; * *$ indicates $\mathrm{p}<0.001$, one-way ANOVA followed by Dunnet's test as compared to control; b.w: body weight.

Table 5. Analgesic activity of the crude ethanolic extract of $T$. pilosa, evaluated by tail immersion method.

\begin{tabular}{|c|c|c|c|c|c|c|}
\hline \multirow{2}{*}{$\begin{array}{l}\text { Test } \\
\text { group }\end{array}$} & \multirow[t]{2}{*}{ Treatment } & \multirow{2}{*}{$\begin{array}{l}\text { Dose } \\
\text { (mg/kg b.w) }\end{array}$} & \multicolumn{4}{|c|}{ Number of movement } \\
\hline & & & $0 \mathrm{~min}$ & $30 \min$ & $60 \mathrm{~min}$ & $90 \mathrm{~min}$ \\
\hline I & $\mathrm{Na}-\mathrm{CMC}$ & $0.1 \mathrm{ml} / \mathrm{mice}$ & $2.0 \pm 0.333$ & $2.5 \pm 0.204$ & $1.66 \pm 0.192$ & $1.46 \pm 0.152$ \\
\hline II & Diclofenac-Na & $5 \mathrm{mg} /$ mice & $1.16 \pm 0.28$ & $1.5 \pm 0.39 * *$ & $1.83 \pm 0.723^{* *}$ & $1.16 \pm 0.597 * *$ \\
\hline III & Extract & $100 \mathrm{mg} / \mathrm{kg}$ & $1.93 \pm 0.192$ & $1.5 \pm 0.39 *$ & $1.63 \pm 0.549 * *$ & $1.77 \pm 0.495^{* *}$ \\
\hline IV & Extract & $200 \mathrm{mg} / \mathrm{kg}$ & $1.99 \pm 0.192$ & $2.7 \pm 0.235^{* *}$ & $2.83 \pm 0.384^{* *}$ & $1.83 \pm 0.561 * *$ \\
\hline V & Extract & $400 \mathrm{mg} / \mathrm{kg}$ & $2.33 \pm 0.192$ & $2.11 \pm 0.235^{* *}$ & $2.77 \pm 0.235^{* *}$ & $1.99 \pm 0.235^{* *}$ \\
\hline
\end{tabular}

Values are expressed as mean $\pm \mathrm{SEM} ;(\mathrm{n}=5) *$ indicates $\mathrm{p}<0.01 ; * *$ indicates $\mathrm{p}<0.001$, one-way ANOVA followed by Dunnet's test as compared to control; b.w: body weight.

Acetic acid-induced writhing test: Dose dependent reduction in the number of abdominal constriction was observed in animals treated with different concentration $(100,200$ and $400 \mathrm{mg} / \mathrm{kg}$ body weight) of ethanol extract of $T$. pilosa and the inhibition of writhing response was observed as $37.18 \%, 42.12 \%$ and $49.22 \%$, respectively as compared to the inhibition of writhing response by diclofenac-Na $(59.11 \%)$. Acetic acidinduced abdominal constrictions are useful experimental tools in the testing of analgesic drugs (Otherness et al., 1985) because the abdominal injection of acetic acid in mice has been attributed to the release of arachidonic acid, which results in the synthesis of prostaglandin via the cyclooxygenase 
enzyme (Davies et al., 1984). When prostaglandin is released, the nerve endings respond to it through prostaglandin E2 receptor by picking up and transmitting the pain and injury messages to the brain and cause visceral writhing stimuli in mice (Ferreira $e t$ al., 1978). Therefore, it has been suggested that the inhibition of prostaglandin synthesis is remarkably an efficient antinociceptive mechanism in visceral pain (Ferreira et al., 1978). Since ethanol extract of T. pilosa showed significant inhibition $(\mathrm{p}<0.001)$ (Table 6) in acetic acid-induced pain, it may be predicted as the analgesic effect produced by the extract.

Table 6. Effect of leaf extract of T. pilosa in acetic acid-induced writhing test on mice.

\begin{tabular}{lccc}
\hline Test group & Doses (mg/kg b.w.) & Number of writhing & \% Inhibition writhing \\
\hline Control (distilled water) & $0.1 \mathrm{ml} / \mathrm{mice}$ & $59.7 \pm 1.47$ & 0.00 \\
Diclofenac-Na & 1.0 & $23.5 \pm 0.78^{* *}$ & 59.11 \\
Group-I & 100 & $36.3 \pm 0.60^{* *}$ & 37.18 \\
Group-II & 200 & $30.4 \pm 0.97^{* *}$ & 42.12 \\
Group-III & 400 & $39.2 \pm 0.73^{* *}$ & 49.22 \\
\hline
\end{tabular}

Values are expressed as mean $\pm \mathrm{SEM}$; ** indicates $\mathrm{p}<0.001$, one-way ANOVA followed by Dunnet's test as compared to control; b.w: body weight

\section{Acknowledgement}

Authors would like to thank the scientists of Bangladesh National Herbarium, Mirpur, Dhaka for identifying the plant.

\section{Conclusion}

Based on the results, we can conclude that the ethanolic extracts of $T$. pilosa and its Kupchon fractions revealed significant in vitro thrombolytic and membrane stabilizing activities and in-vivo antidiarrhoeal and analgesic activities. It may be stated that the extracts can be considered as appropriate agent with thrombolytic, antidiarrhoeal, membrane stabilizing and analgesic activities. These might be due to the presence of substantial amount of flavonoids and tannins in the crude extract.

\section{References}

Ahmadiani, A., Hosseiny, J., Semnanian, S., Javan, M., Saeedi, F. and Kamalinejad, M. 2000. Antinociceptive and anti-inflammatory effects of Elaeagnus angustifolia fruit extract. J Ethnopharmacol. 72, 287-292.

Burdock, G.A., Carabin, I.G. and Griffiths, J.C. 2006. Toxicology and pharmacology of sodium ricinoleate. Food Chem. Toxicol. 44, 1689-1698.
Chang, C., Yang, M., Wen, H. and Chern, J. 2002. Estimation of total flavonoid content in propolis by two complementary colorimetric methods. J. Food Drug Anal. 10,178-182.

D'Amour, F.E. and Smith, D.L. 1941. A method for determining loss of pain sensation. J. Pharmacol. Exp. Ther. 72, 74-79.

Daginawala, H.F., Prasad, S., Kashyap, R.S., Deopujari, J.W. and Purothi, H.J. 2006. Development of an in vitro model to study clot lysis activity of thrombolytic drugs. Thrombosis J. 4, 14.

Davies, P., Bailey, P.J., Goldenberg, M.M. and FordHutchinson, A.W. 1984. The role of arachidonic acid oxygenation products in pain and inflammation. Ann. Rev. Immunol. 2, 335-357.

Farnsworth, N.R. 1966. Biological and phytochemical screening of plants. J. Pharm. Sci. 55, 225-276.

Franzotti, E.M., Santos, C.V., Rodrigues, H.M., Mourão, R.H. and Andrade, M.R. 2002. J Ethnopharmacol. 72, 273278.

Ferreira, S., Nakamura, M. and Abreu Castro, M. 1978. The hyperalgesic effects of Prostacyclin and PGE2. Prostaglandins 16, 31-38.

Kirtikar, K.R. and Basu, B.D. 1993. Indian Medicinal Plants. India: Bishen Singh and Mahendra Pal Singh. 1, 496498. 
Kumaran, A. and Karunakaran, R.J. 2004. In vitro antioxidant properties of methanol extracts of five Phyllanthus species from India. LWT-Food Sci Technol. 4, 344-352.

Kim, D.O., Jeong, S.W. and Lee, C.Y. 2003. Antioxidant capacity of phenolic phytochemicals from various cultivars of plums. Food Chem. 81, 321-326.

Koster, R. and Anderson, M.1959. Acetic acid for analgesic screening. Fed. Proc. 18, 412-416.

Oluyemi, K.A., Okwuonu, U.C., Baxter, D.G. and Oyesola, T.O. 2007. Toxic effects of methanolic exract of Aspilia africana leaf on the estrous cycle and uterine tissues of Wistar rats. Int J. Morphol. 25, 609-614.

Otterness, I. and Bliven, M. 1985. Laboratory models for testing nonsteroidal antiinflammatory drugs. In Nonsteroidal antiinflammatory drugs. J. Lombardino, editor. John Wiley \& Sons Inc. New York, New York, USA pp. 112-251.

Rabanal, R.M. Bonkanka, C.X., Hernandez, P. and Sanchez, M.C. 2005. Analgesic and topical anti-inflammatory activity of Hypericum canariense L. and Hypericum glandulosum Ait. J. Ethnopharmacol. 9, 591-596.

Shinde, U.A., Phadke, A.S. and Nair, A.M. 1989. Membrane stabilization activity- a possible mechanism of action for the anti-inflammatory activity of Cedrus deodara wood oil. Fitoterapia. 70, 251-257.

Shoba, F.G. and Thomas, M. 2001. Study of antidiarrheal activity of four medicinal plants in castor oil-induced diarrhea. J. Ethnopharmacol. 76, 73-76.

Sajeli, B., Bhagawati, S., Madhur, G., Rakesh, R. and Vijaya, B.J. 2010. Study of anti-inflammatory, analgesic and antipyretic activities of seeds of Hyoscyamus niger and isolation of a new coumarinolignan. Fitoterapia 81, 178-184.

Shulan, S., Tuanjie, W., Jino, D. and Wei, Z. 2011. Antiinflammatory and analgesic activity of different extracts of Commiphora myrrha. J. Ethnopharmacol. 134, 251258.

Sofowora, A.1993. Medicinal Plants and Traditional Medicine in Africa. 2nd Ed. Sunshine House, Ibadan, Nigeria: Spectrum Books Ltd; Screening Plants for Bioactive Agents; pp. 134-156.

Vongtau, H.O., Abbah, J. and Chindo, B.A. 2005. Central inhibitory effects of the methanol extract of Neorautanenia mitis root in rats and mice. J. Pharm Biol. 43, 113-120.

Watson, W.C. and Gordon, R.S. 1962. Studies on the digestion, absorption and metabolism of castor oil. Biochem Pharmacol. 11, 229-236.

Zengin, G., Aktumsek, A., Guler, G.O., Cakmak, Y.S. and Kan, Y. 2012. Composition of essential oil and antioxidant capacity of Centaurea drabifolia Sm. subsp. Detonsa (Bornm.) Wagenitz, endemic to Turkey. Nat. Prod. 26, 1-10.

Zhang, Y.J., Tanaka, T., Iwamoto, Y., Yang, C.R. and Kouno, I. 2001. Novel sesquiterpenoids from the roots of Phyllanthus emblica. J. Nat. Prod. 64, 870- 873. 